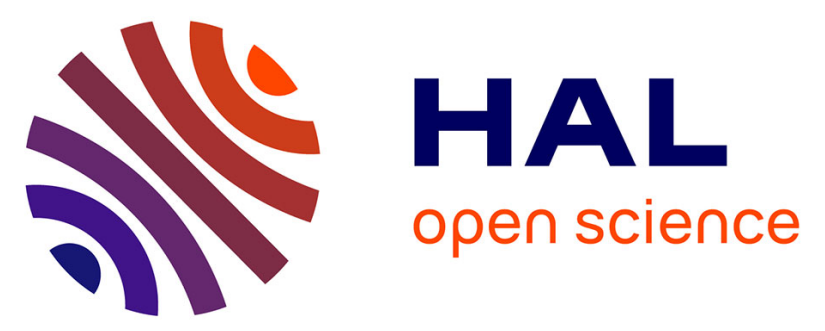

\title{
Penetration and cratering experiments of graphite by 0.5-mm diameter steel spheres at various impact velocities
}

Gabriel Seisson, D. Herbert, L. Hallo, J.M Chevalier, F. Guillet, Laurent Berthe, M. Boustie

\section{To cite this version:}

Gabriel Seisson, D. Herbert, L. Hallo, J.M Chevalier, F. Guillet, et al.. Penetration and cratering experiments of graphite by 0.5 - $\mathrm{mm}$ diameter steel spheres at various impact velocities. International Journal of Impact Engineering, 2014, 70, pp.14-20. 10.1016/j.ijimpeng.2014.03.004 • hal-00980178

\section{HAL Id: hal-00980178 https://hal.science/hal-00980178}

Submitted on 17 Apr 2014

HAL is a multi-disciplinary open access archive for the deposit and dissemination of scientific research documents, whether they are published or not. The documents may come from teaching and research institutions in France or abroad, or from public or private research centers.
L'archive ouverte pluridisciplinaire HAL, est destinée au dépôt et à la diffusion de documents scientifiques de niveau recherche, publiés ou non, émanant des établissements d'enseignement et de recherche français ou étrangers, des laboratoires publics ou privés. 


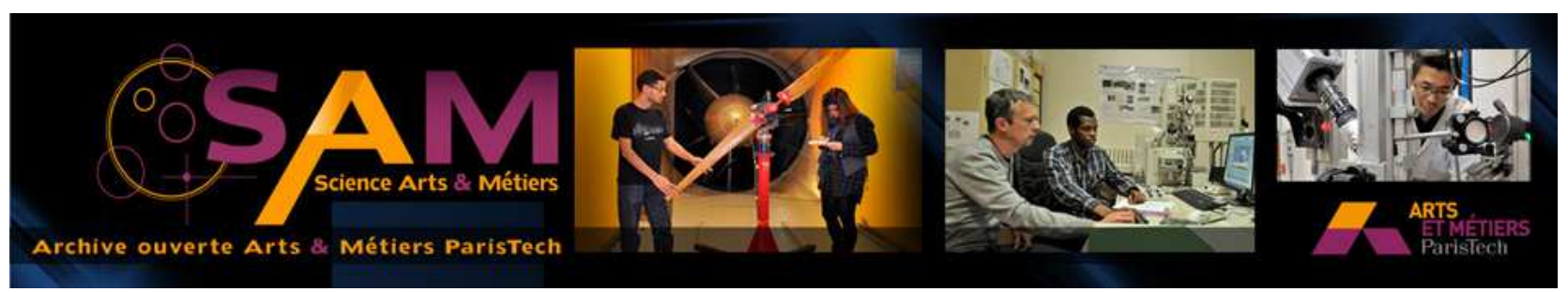

\section{Science Arts \& Métiers (SAM)}

is an open access repository that collects the work of Arts et Métiers ParisTech researchers and makes it freely available over the web where possible.

This is an author-deposited version published in: http://sam.ensam.eu

Handle ID: .http://hdl.handle.net/10985/7974

\section{To cite this version :}

G SEISSON, D HEBERT, L HALLO, J.M CHEVALIER, F GUILLET, Laurent BERTHE, M BOUSTIE - Penetration and cratering experiments of graphite by $0.5-\mathrm{mm}$ diameter steel spheres at various impact velocities - International Journal of Impact Engineering - Vol. 70, p.14-20 - 2014 


\title{
Penetration and cratering experiments of graphite by $0.5-\mathrm{mm}$ diameter steel spheres at various impact velocities
}

\author{
G. Seisson ${ }^{\mathrm{a}, *}$, D. Hébert ${ }^{\mathrm{a}}$, L. Hallo ${ }^{\mathrm{a}}$, J.-M. Chevalier ${ }^{\mathrm{a}}$, F. Guillet ${ }^{\mathrm{b}}$, L. Berthe ${ }^{\mathrm{c}}$, M. Boustie ${ }^{\mathrm{d}}$ \\ ${ }^{a}$ CEA CESTA, 15 avenue des Sablières CS60001, 33116 Le Barp Cedex, France \\ ${ }^{\mathrm{b}}$ CEA LR, BP16, 37260 Monts, France \\ ${ }^{c}$ Laboratoire PIMM UPR8006 CNRS-Arts et Métiers ParisTech, 151 boulevard de l'Hôpital, 75013 Paris, France \\ 'Institut P' UPR3346 CNRS-ENSMA-Université de Poitiers, 1 avenue Clément Ader, 86961 Futuroscope Cedex, France
}

Keywords:

Cratering

Penetration

Graphite

Hyper-velocity impact

Projectile trapping

\begin{abstract}
A B S T R A C T
Cratering experiments have been conducted with 0.5-mm diameter AISI 52100 steel spherical projectiles and $30-\mathrm{mm}$ diameter, $15-\mathrm{mm}$ long graphite targets. The latter were made of a commercial grade of polycrystalline and porous graphite named EDM3 whose behavior is known as macroscopically isotropic. A two-stage light-gas gun launched the steel projectiles at velocities between 1.1 and $4.5 \mathrm{~km} \mathrm{~s}^{-1}$. In most cases, post-mortem tomographies revealed that the projectile was trapped, fragmented or not, inside the target. It showed that the apparent crater size and depth increase with the impact velocity. This is also the case of the crater volume which appears to follow a power law significantly different from those constructed in previous works for similar impact conditions and materials. Meanwhile, the projectile depth of penetration starts to decrease at velocities beyond $2.2 \mathrm{~km} \mathrm{~s}^{-1}$. This is firstly because of its plastic deformation and then, beyond $3.2 \mathrm{~km} \mathrm{~s}^{-1}$, because of its fragmentation. In addition to these three regimes of penetration behavior already described by a few authors, we suggest a fourth regime in which the projectile melting plays a significant role at velocities above $4.1 \mathrm{~km} \mathrm{~s}^{-1}$. A discussion of these four regimes is provided and indicates that each phenomenon may account for the local evolution of the depth of penetration.
\end{abstract}

\section{Introduction}

One of the major concerns for spacecraft or high-power laser applications is the cratering process in brittle materials under highand hyper-velocity impacts (HVI). Among them, carbon is of particular interest because it is a common elementary component in composite materials. Indeed, they are widely used in aerospace industry owing to their low density and high mechanical properties. In that specific case, meteoroids may impact satellites at several kilometers per second, possibly damaging or destroying some vital equipment [1,2], such as tanks. Moreover, the ejection of secondary debris created by previous impacts can remain on orbital trajectories and hit other man-made space structures [3]. Similarly, the various instruments used in the Laser MégaJoule (LMJ) experiment chamber may be struck by a variety of shrapnel and debris originating from the target assembly after intense laser shots [4,5].

\footnotetext{
* Corresponding author.

E-mail addresses:

(G. Seisson).
}

The range of materials exposed to HVI is significant. Metals have been widely studied, both experimentally [6-9] and through the use of numerical hydrocodes [10]. Brittle materials have also been included in previous studies, such as geophysical materials [11], silica glass [12,13] or building materials [14-16]. For the latter, the depth of penetration (DOP) is particularly analyzed as a performance criterion. Concerning composites, studies have already been conducted [17,18], but it appears there is a lack of knowledge about damaging and cratering processes of elementary components such as graphite matrix or fibers. Experimental results have been published giving crater dimensions in porous graphite for a variety of projectile materials and velocities $[19,20]$. The present authors have attempted to compute numerical models into hydrocodes to reproduce experimental results [21]. However, a large set of experimental data was missing in order to fit the parameters of the models, especially that of the projectile such as elastic limit and strength which may be highly dependent of the strain rate [22].

In this paper, we present experiments leading to crater formation and penetration of a steel projectile into a commercial grade of polycrystalline graphite. In the following section, we describe the dynamic experiments on thick targets and display new results. 
Then, Section 3 will be devoted to the discussion of the data obtained by post-mortem tomographies on the recovered samples. Finally, in Section 4, we will try to get a better insight into the penetration processes.

\section{Experimental}

We recently conducted cratering experiments with $0.5-\mathrm{mm}$ diameter AISI 52100 steel spherical projectiles and 30-mm diameter, $15-\mathrm{mm}$ long graphite targets. This graphite is a commercial grade from the POCO company [23] and is macroscopically isotropic with a density of $1754 \mathrm{~kg} \mathrm{~m}^{-3}$. Its main mechanical characteristics have been published in Ref. [24] and are recalled in Table 1 along with those of hardened AISI 52100 steel. Indeed, projectiles stem from bearings involving a high Rockwell hardness in the 60-65 HRC range. They were launched by MICA, a twostage light-gas gun described in a previous work [21] at velocities from 1.1 to $4.5 \mathrm{~km} \mathrm{~s}^{-1}$. They orthogonally impacted the cylindrical graphite targets creating a crater on the front surface. Post-mortem tomographies revealed that, in most cases, the projectile remains are buried into the sample. It also gave the main dimensions such as diameter, depth and volume of the apparent crater and the maximum depth of the projectile. The shot characteristics and the dimensions are summarized in Table 2. Note that the projectile has not been found in the sample for shots \#38_09 and \#41_09.

\section{Discussion of the experimental results}

\subsection{Crater depth and diameter}

The crater diameters and depths normalized by the projectile diameter are plotted in Fig. 1. As expected, they strictly increase with the impact velocity, apparently following a power law. Previous studies about spherical projectiles impacting various ductile materials used a $2 / 3$ power law which is linked to the hemispherical shape of the resulting craters [6,7]. However, in the study of steel spheres impacting graphite brittle targets, Tanabe et al. [19] have noticed the same law with conical craters though. In our case, even if the craters are also conical (cf. Fig. 5), the exponents of the fitting power laws are closer to 1.2 and 1.6.

Regarding the two shots \#38_09 and \#41_09 where the projectile has not been found, one can note that the crater diameters and depths are slightly out of line. It can be explained by the impact of a debris originating from the launcher instead of the steel projectile. For these reasons, we did not consider these two shots in the following analysis and discussions.

Table 1

Main mechanical characteristics of EDM3 graphite [23,24] and AISI 52100 steel $[25,26]$.

\begin{tabular}{llll}
\hline & EDM3 & & Hardened AISI 52100 \\
\hline Density $\rho_{0}\left(\mathrm{~kg} \mathrm{~m}^{-3}\right)$ & Porous & 1754 & 7800 \\
& Compact & 2265 & \\
Young's modulus $E(\mathrm{GPa})$ & Tension & 11 & 208 \\
& Compression & 12 & \\
Failure stress $\sigma_{\mathrm{r}}(\mathrm{MPa})$ & Tension & 70 & $2150-2450$ \\
& Compression & 140 & \\
Failure strain $\varepsilon_{\mathrm{r}}(\%)$ & Tension & 1 & $1-2$ \\
& Compression & 8 & \\
Bulk wave velocity $C_{0}\left(\mathrm{~m} \mathrm{~s}^{-1}\right)$ & 2212 & $4500-4600$ \\
Fracture toughness $K_{\mathrm{Ic}}\left(\mathrm{MPa} \mathrm{m}^{1 / 2}\right)$ & $0.8-1.2$ & $15-20$ \\
Porosity $(\%)$ & $\sim 20$ & - \\
\hline
\end{tabular}

\subsection{Crater volume}

Many previous studies on ductile materials have emphasized that in the hyper-velocity regime the crater shape moves towards a hemisphere and the volume becomes proportional to the kinetic energy of the projectile, i.e. $V_{\mathrm{c}} \propto v_{0}^{2}[6,7]$. For brittle materials, things are rather different especially in the particular case of polycrystalline graphite.

For impacts of steel spheres onto graphite targets, Latunde-Dada et al. [20] have demonstrated a good correlation between the measured crater volume and an approximated conical one using the depth and the diameter as characteristic dimensions. Regarding Fig. 5 and Table 2, it is relevant for the present shots with similar materials whereas the hemispherical approximation would clearly overestimate it.

Following the work of previous authors, Tanabe et al. [19] linked the crater volume not only to the impact velocity but also to the static mechanical properties of the target such as fracture toughness, hardness and elastic modulus. It resulted in a velocity exponent close to 5/2. In Ref. [20], Latunde-Dada et al. proposed no correlation between impact speed and crater volume. However, their data are plotted in Fig. 2 along with the crater volume from our experiments. In both the studies, the projectile is a steel sphere and the targets are made of graphite with a very similar density. It appears that in both cases the volume $V_{\mathrm{c}}$ is not proportional to $v_{0}^{2}$. More surprising is the fact that the exponent is around 2.6 for Latunde-Dada et al. when it is 4 for us, despite the sameness of the materials at stake. We have no satisfying explanation for that but it clearly shows that the respective density of the projectile and the target are not the only relevant characteristics in predicting the crater volume evolution. However, the trapping phenomenon occurring in our study forces us to consider the results with caution. This is especially true, since Latunde-Dada et al. did not mention it in their original work, but maybe because no further experimental analysis had been conducted.

\subsection{Depth of penetration}

For every shot considered here, the steel spherical projectile is trapped, fragmented or not, into the graphite target. Call depth of penetration (DOP) the position of its deepest fragment relatively to the impacted surface.

Fig. 3 presents the projectile DOP versus the impact velocity. Unlike the crater diameters, depths and volumes, the DOP is not strictly increasing but decreases beyond $2.2 \mathrm{~km} \mathrm{~s}^{-1}$. This phenomenon has already been observed in previous works for various projectiles and targets (non-exhaustive): spherical-nose and ogivenose steel projectiles onto aluminum targets [8,9]; adobe bricks impacted by steel, aluminum and titanium spheres of various diameters [14]; ogive-nose steel projectiles striking concrete targets [16]; steel spheres into low density media such as sand [27]. The authors generally explain this result by the erosion, the deformation and/or the fragmentation of the projectile beyond a speed threshold, but with no further analysis. However, Trucano and Grady [28] highlighted three regimes of penetration behavior for spherical copper projectiles striking polyurethane foam targets. In the first one, at the lowest impact velocities, they noted the erosion of the projectile with a low mass loss and almost no deformation. In the second one, the erosion continues and the projectile is strongly deformed and flattened. Its mass loss is four times higher. In the last regime, for the highest velocities, they observed the multiple fragmentation of the spherical projectile.

From Fig. 3, one may identify three different speed ranges possibly corresponding to the three regimes of penetration behavior described by Trucano and Grady: 
Table 2

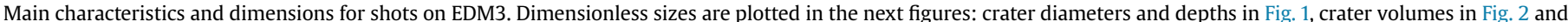

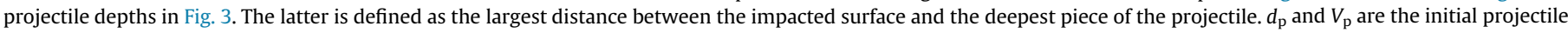
diameter and volume, respectively.

\begin{tabular}{|c|c|c|c|c|c|c|c|c|c|}
\hline \multirow[t]{2}{*}{ Shot number } & \multirow{2}{*}{$\frac{\text { Proj. velocity }}{v_{0}\left(\mathrm{~m} \mathrm{~s}^{-1}\right)}$} & \multirow{2}{*}{$\frac{\text { Crater depth }}{p_{\mathrm{c}}(\mathrm{mm})}$} & \multirow{2}{*}{$\frac{\text { Crater diam. }}{d_{\mathrm{c}}(\mathrm{mm})}$} & \multirow{2}{*}{$\frac{\text { Crater vol. }}{V_{\mathrm{c}}\left(\mathrm{mm}^{3}\right)}$} & \multirow{2}{*}{$\frac{\text { Proj. depth }}{p_{\mathrm{p}}(\mathrm{mm})}$} & \multicolumn{4}{|c|}{ Dimensionless sizes } \\
\hline & & & & & & $p_{c} / d_{\mathrm{p}}$ & $d_{c} / d_{\mathrm{p}}$ & $p_{\mathrm{p}} / d_{\mathrm{p}}$ & $V_{\mathrm{c}} / V_{\mathrm{p}}$ \\
\hline 02_12 & 1168 & 0.26 & 0.96 & 0.05 & 2.53 & 0.52 & 1.92 & 5.06 & 0.76 \\
\hline 03_12 & 1695 & 0.40 & 1.28 & 0.15 & 4.02 & 0.80 & 2.56 & 8.04 & 2.29 \\
\hline 01_12 & 1753 & 0.38 & 1.20 & 0.11 & 4.07 & 0.76 & 2.40 & 8.14 & 1.68 \\
\hline 68_13 & 1872 & 0.43 & 1.38 & 0.21 & 4.36 & 0.86 & 2.75 & 8.72 & 3.21 \\
\hline 70_13 & 2445 & 0.54 & 1.69 & 0.33 & 4.52 & 1.08 & 3.38 & 9.04 & 5.04 \\
\hline 72_13 & 2685 & 0.74 & 1.86 & 0.59 & 4.22 & 1.48 & 3.72 & 8.44 & 9.01 \\
\hline 71_13 & 2856 & 0.94 & 2.07 & 0.71 & 3.84 & 1.88 & 4.13 & 7.68 & 10.85 \\
\hline 38_09 & 3072 & 1.29 & 3.21 & 3.43 & - & 2.58 & 6.42 & - & 52.41 \\
\hline 120_12 & 3446 & 1.34 & 3.16 & 3.68 & 2.59 & 2.68 & 6.31 & 5.18 & 56.23 \\
\hline 41_09 & 3788 & 0.94 & 2.94 & 2.80 & - & 1.88 & 5.88 & - & 42.78 \\
\hline 41_01 & 3895 & 1.42 & 3.42 & 3.60 & 2.62 & 2.84 & 6.84 & 5.24 & 55.00 \\
\hline 38_01 & 4003 & 1.46 & 3.37 & 3.90 & 2.75 & 2.92 & 6.74 & 5.50 & 59.59 \\
\hline 39_09 & 4348 & 1.42 & 3.64 & 5.16 & 2.28 & 2.84 & 7.28 & 4.56 & 78.84 \\
\hline 21_01 & 4512 & 1.85 & 3.95 & 6.30 & 2.31 & 3.70 & 7.89 & 4.62 & 96.26 \\
\hline
\end{tabular}

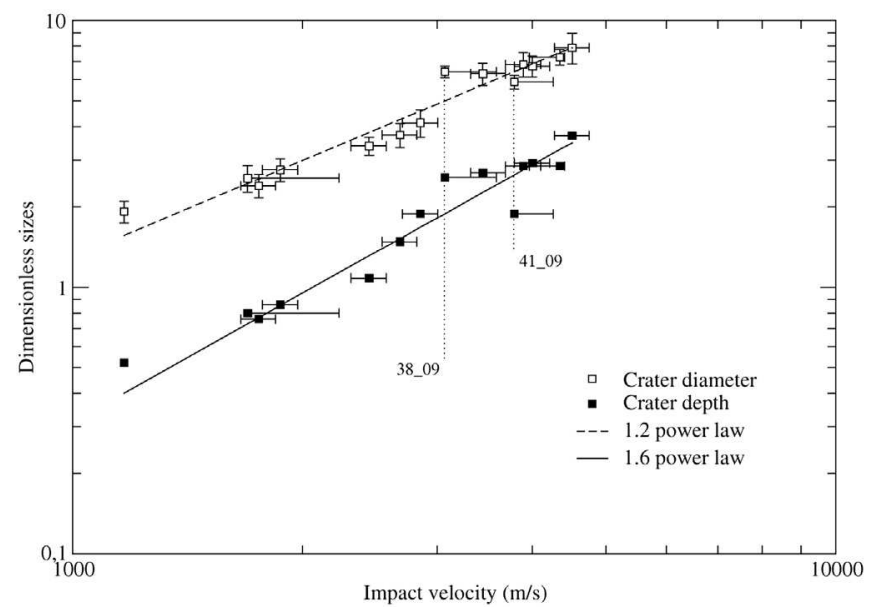

Fig. 1. Crater diameter and depth (from tomographic slices), both normalized by projectile diameter, versus impact velocity. Error bars on impact velocities and diameters are given when known. Two shots are ignored hereinafter: \#38_09 and \#41_09 (see text for more details).

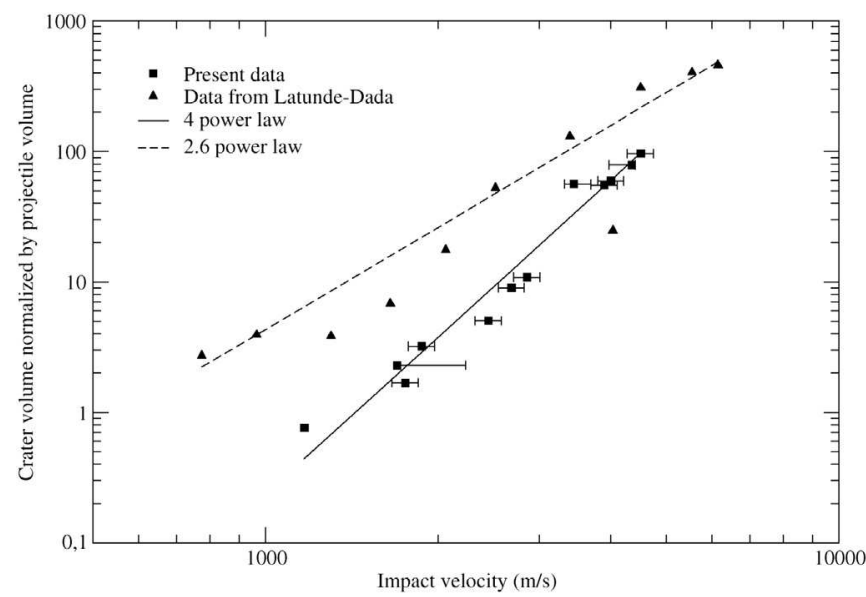

Fig. 2. Crater volume normalized by the projectile volume and plotted versus the impact velocity. Volumes of shots \#38_09 and \#41_09 are not displayed. Data from Latunde-Dada et al. [20] are also presented (see text for more details). There is no velocity uncertainty available for those.
- The first one (call it R1) goes from 0 to about $2.2 \mathrm{~km} \mathrm{~s}^{-1}$, where the DOP seems to linearly increase with the velocity (despite the lack of data around $1 \mathrm{~km} \mathrm{~s}^{-1}$ ) which is consistent with Ref. [14].

- In the next part (R2), the DOP strongly goes down until a velocity near $3.2 \mathrm{~km} \mathrm{~s}^{-1}$ is reached.

- Finally, beyond the latter velocity (R3), the DOP decreases more slowly, being almost constant.

This description is corroborated by Fig. 4. It displays 3D-reconstructions of projectiles from post-mortem tomographies and sets them up into the velocity-DOP plane. For the sake of clarity, only representative shots of each regime are presented but every shot has been analyzed and is consistent with one another. It confirms that, for the first regime (R1), the projectile is only slightly deformed. As expected in R2, the higher the velocity, the stronger the plastic deformations and the lower the DOP. In R3, the projectile is divided into multiple fragments and the DOP seems stabilized. However, by this figure we underlie the existence of a fourth regime (call it $\mathrm{R}^{\prime}$ ): past an impact velocity of around $4.1 \mathrm{~km} \mathrm{~s}^{-1}$, the projectile is still fragmented but the physical aspect of its fragments suggests they were melted (at least partially).

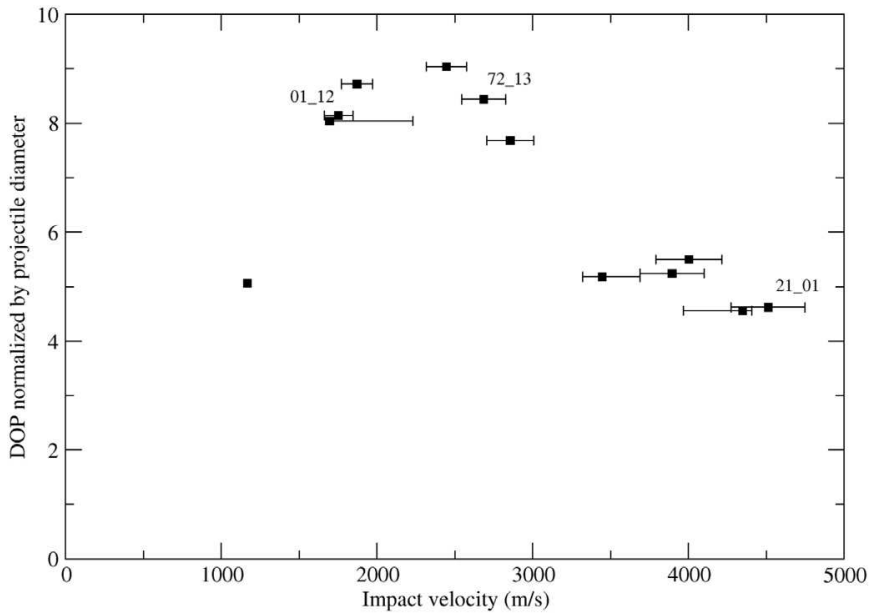

Fig. 3. Projectile depth (from tomographic slices) normalized by projectile diameter with regards to impact velocity. It increases up to $2.2 \mathrm{~km} \mathrm{~s}^{-1}$ and decreases strongly under $3.2 \mathrm{~km} \mathrm{~s}^{-1}$ and almost constant beyond. The DOP is the largest distance between the impacted surface and the deepest piece of the projectile. 


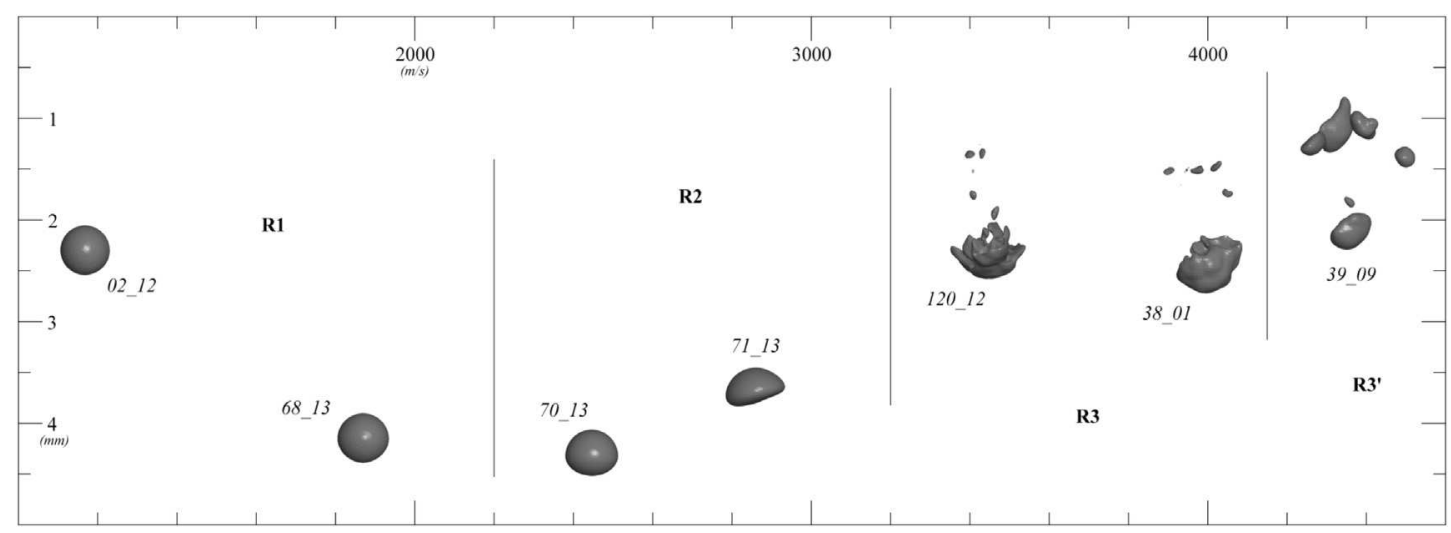

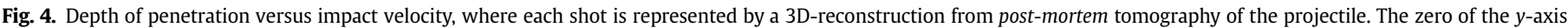

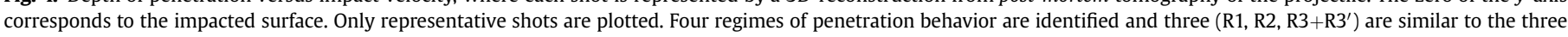
observed by Trucano and Grady [28].

Erosion is clearly visible in the R1 and R2 regimes. In Fig. 5, it takes the form of a milky trail existing in the projectile path through the graphite target. This is less obvious but still present for the third regime because of the shorter path. However, in the last regime the erosion is not observable because the remains of the projectile are right behind the crater bottom. In each case, the mass loss is hardly measurable but the analysis of the projectile volumes from 3D-reconstructions reveals that it is surely less than $10 \%$ of the original mass. Note that the precision of this estimation is directly linked to the resolution of the tomographies (here between 13 and $20 \mu \mathrm{m} / \mathrm{px})$.

In conclusion, we have experimentally evidenced three different regimes of penetration behavior in graphite already observed by previous authors for other materials. Nonetheless, we support the existence of a fourth regime in which the fragmentation aspect of the projectile suggests a significant melting. The next section is devoted to the correlation between the DOP and the different phenomena observed in each regime.

\section{Discussion of the evolution of the DOP}

\subsection{Penetration without fragmentation (R1 and $R 2$ )}

Here, we try to explain by two methods the successive increasing and decreasing of the projectile depth of penetration below $3.2 \mathrm{~km} \mathrm{~s}^{-1}$.

Take for example two shots with similar DOP yet different velocities, \#68_13 (R1) and \#72_13 (R2). It implies that the kinetic energy of the second is about $1 \mathrm{~J}$ greater than the first one. Consequently, the projectile of the second should be the deepest but that is not the case. Considering that \#72_13 belongs to the regime where the projectile suffers plastic deformations, one may suppose that they have consumed the extra amount of kinetic energy. For an upper value of the plastic deformation of the projectile $\varepsilon_{\mathrm{p}}^{\mathrm{p}} \sim 1$, a yield stress estimated at $Y_{\mathrm{p}} \sim 2.5 \mathrm{GPa}$ and a projectile volume $V_{\mathrm{p}} \sim 6 \times 10^{-11} \mathrm{~m}^{3}$, the plastic deformation energy is

$E_{\mathrm{p}}^{\mathrm{p}}=Y_{\mathrm{p}} \varepsilon_{\mathrm{p}}^{\mathrm{p}} V_{\mathrm{p}} \sim 150 \mathrm{~mJ}$

This is much less than the difference of kinetic energy between the two shots. Thus, the energy of plastic deformation cannot thoroughly justify the fact that two shots with different velocities may have similar DOP.

However, if we assume that the projectile flattening occurs at the very first instant of the penetration process, the surface area increasing and the shape modification may be responsible for the
DOP diminution. According to the Newton's second law, we can describe the velocity variation through time by

$-\alpha P S=m \frac{\mathrm{d} v}{\mathrm{~d} t}$

where $P$ is the pressure at the interface between the projectile and the target. $S$ is the apparent surface area of the projectile in the penetration direction, $m$ its mass, $v$ its velocity and $\alpha$ is a shape coefficient. The effects of the friction and the erosion of the projectile are neglected. To the first order, the pressure can be approximated by $P=\rho_{0} C_{0} u$ with $\rho_{0}$ and $C_{0}$ the initial target density and bulk wave velocity, respectively. Note that the use of shock wave theory for estimating the pressure is accurate only when the latter is higher than the elastic limit of the target material. In the case of the lowest impact velocity, the impact pressure is around $4 \mathrm{GPa}$. It suggests that the assumption is correct for each shot neglecting the very end of the penetration process when the pressure becomes less than $\sim 100 \mathrm{MPa}$. The particle velocity $u$ is related to the projectile velocity by $u=Z v$, where the impedance mismatch $Z$ is equal to 1.14 in this case. Thus, rounding the latter to 1 , take $P=\rho_{0} C_{0} v$ hereinafter. Eq. (2) becomes a differential equation giving the projectile depth as a function of time $p_{\mathrm{p}}(t)$ :

$\frac{\mathrm{d}^{2} p_{\mathrm{p}}(t)}{\mathrm{d} t^{2}}+A \frac{\mathrm{d} p_{\mathrm{p}}(t)}{\mathrm{d} t}=0 \quad$ with $A=\frac{\alpha \rho_{0} C_{0} S}{m}$

Solving the latter equation leads to the general solution:

$p_{\mathrm{p}}(t)=\frac{v_{0}}{A}\left(1-e^{-A t}\right)$

It finally gives a linear relation between the projectile depth of penetration $p_{\mathrm{p}}$ and the initial velocity $v_{0}$ when $t \rightarrow \infty$ :

$p_{\mathrm{p}}=\frac{v_{0}}{A}=\frac{m}{\alpha \rho_{0} C_{0} S} v_{0}$

For the seven shots without fragmentation, the use of Eq. (5) can display the evolution of the shape coefficient $\alpha$ according to the impact velocity $v_{0}$ (cf. Fig. 6 ). For regime R1, the apparent surface area $S$ is constant and equal to that of the initial spherical projectile. $\alpha$ appears to be constant except for shot \#02_12 (R1), but it can be explained by $5 \%$ of uncertainties on the impact velocity. It confirms that the friction effects and the erosion are negligible phenomena. Note that our shape coefficient $\alpha$ as the same order of magnitude than the drag coefficient of a solid sphere in a fluid for the subsonic laminar regime $\left(C_{D} \sim 0.5\right)$. However, the analogy cannot be taken 


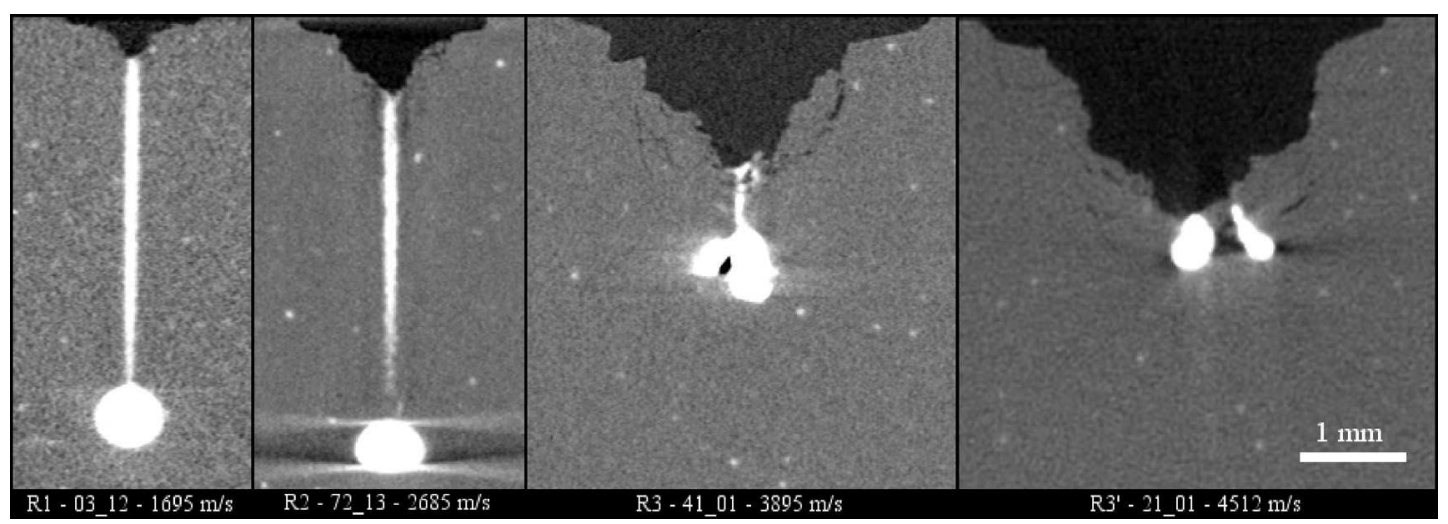

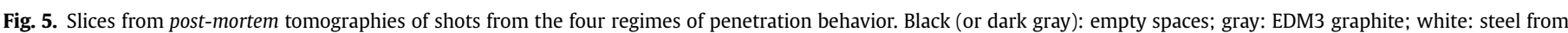

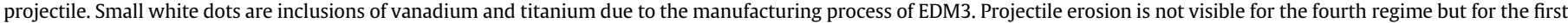

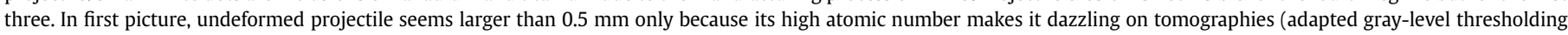
was able to correct that before 3D-reconstruction).

any further because the flows are substantially different in solids. In $\mathrm{R} 2, S$ is measured thanks to tomographies but its increase cannot entirely explain the DOP diminution. Therefore $\alpha$ also increases in this regime which shows the shape effect on the projectile penetration.

Beyond $3.2 \mathrm{~km} \mathrm{~s}^{-1}$, the multiple fragmentations of the projectile and its probable melting do not allow the use of this simple penetration model in order to entirely justify the DOP decrease.

\subsection{Multiple fragmentation of the projectile ( $R 3$ and $R 3^{\prime}$ )}

In Section 2, we named R3 the regime of penetration behavior at velocities between 3.2 and $4.1 \mathrm{~km} \mathrm{~s}^{-1}$ where the projectile is fragmented. In that case, the DOP is significantly smaller than for the shots from R1 and R2. As demonstrated above, the part of the kinetic energy of the projectile consumed by its plastic deformation is negligible and thus not sufficient to explain that difference. Nevertheless, its multiple fragmentation is bound to play a substantial role in the reduction of the DOP.

The most immediate reason of this phenomenon is the dispatch of the original mass between smaller debris. It is very likely that the fragmentation process occurs at the first instant of the penetration,

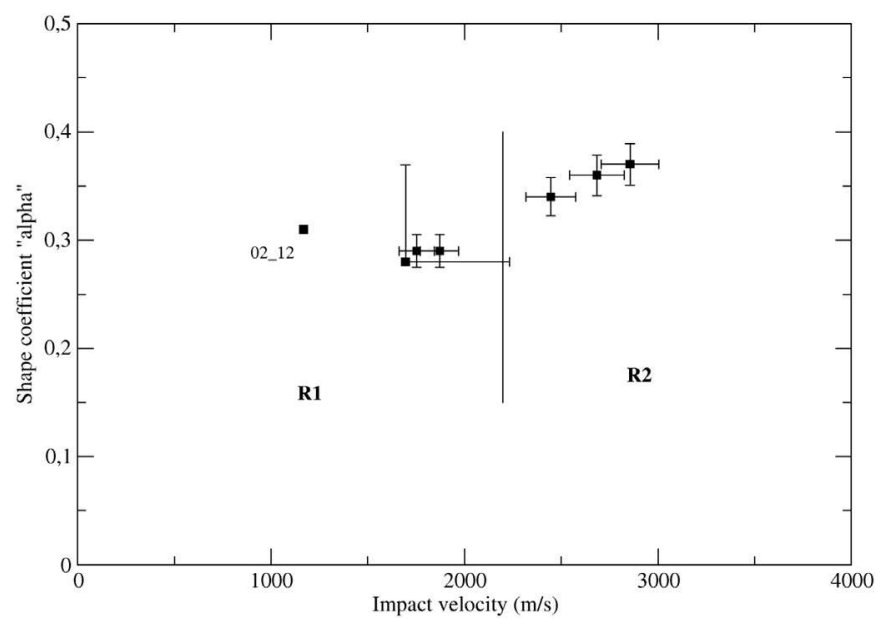

Fig. 6. Shape coefficient $\alpha$ versus impact velocity $v_{0}$. Error bars come from uncertainties on the impact velocity. It is quite constant in $\mathrm{R} 1$, where the projectile stays undeformed. Thus the erosion does not play a significant role. When the projectile is flattened by the impact (R2), the shape coefficient increases with the impact velocity. right after the impact. In that case and assuming spherical shapes, debris have a lower penetration capability because of the sectional density $m / S \propto r$ being smaller in Eq. (5), with $r$ the projectile or debris radius. Thus, this is a scaling phenomenon accentuated by the flattened shape of the debris (see Fig. 7) that decreases further the ratio of $m$ and $S$ and increases their drag coefficient. However, the complexity of this phenomenon makes it impossible to be modeled by a simple penetration calculation such as in Section 4.1, although there is no contradiction with it.

A cumulative cause could be the consumption of a substantial part of the original kinetic energy by new surface creation. Fig. 7 presents three side-views of the projectile remains from shot \#38_01. These high-resolution tomographic data $(1.6 \mu \mathrm{m} / \mathrm{px})$ enable to estimate a surface area created by fragmentation but necessarily underestimate it, due to their finite resolution. Thus, the surface creation $S_{\text {frag }} \geq 2.25 \mathrm{~mm}^{2}$ is at least three times the surface area of the original spherical projectile. The fracture energy per unit surface $\gamma$ is given by the Irwin formula as a function of the fracture toughness $K_{\mathrm{Ic}}$, the Poisson ratio $\nu$ and the Young's modulus $E$ of the considered material:

$\gamma=K_{\mathrm{Ic}}^{2} \frac{\left(1-\nu^{2}\right)}{2 E}$

According to Bhadeshia [25], most of the standard AISI 52100 steels hardened to $60-65 \mathrm{HRC}$ have fracture toughness in the range of $15-20 \mathrm{MPa} \mathrm{m}{ }^{1 / 2}$. With $\nu=0.3$ and $E=208 \mathrm{GPa}$, the fracture energy of the material is thus between 500 and $900 \mathrm{~J} \mathrm{~m}^{-2}$. In these conditions, the part of the kinetic energy dissipated by the projectile fragmentation cannot be higher than a few mJ. This is not significant with regard to the $4.1 \mathrm{~J}$ of the projectile kinetic energy. Then, it turns out that the fragmentation energy does not play a significant role in DOP decreasing, contrary to the energy partitioning between the projectile debris.

Previously, we defined R3' as the regime of penetration behavior beyond $4.1 \mathrm{~km} \mathrm{~s}^{-1}$ comparable in all respects to R3, except for the appearance of the projectile fragments which suggests a significant melting. In that case, they should be highly malleable and easily flattened which would increase their apparent surface yet with a constant mass. Note that their shape observable on tomographies is certainly far different from that during the penetration process because of the re-closing of graphite after impact. Thus, their penetration power should be much less than that of solid fragments and this fact may account for the quasi-constant DOP between R3 and $\mathrm{R}^{\prime}$. Moreover, the extra amount of kinetic energy available in 

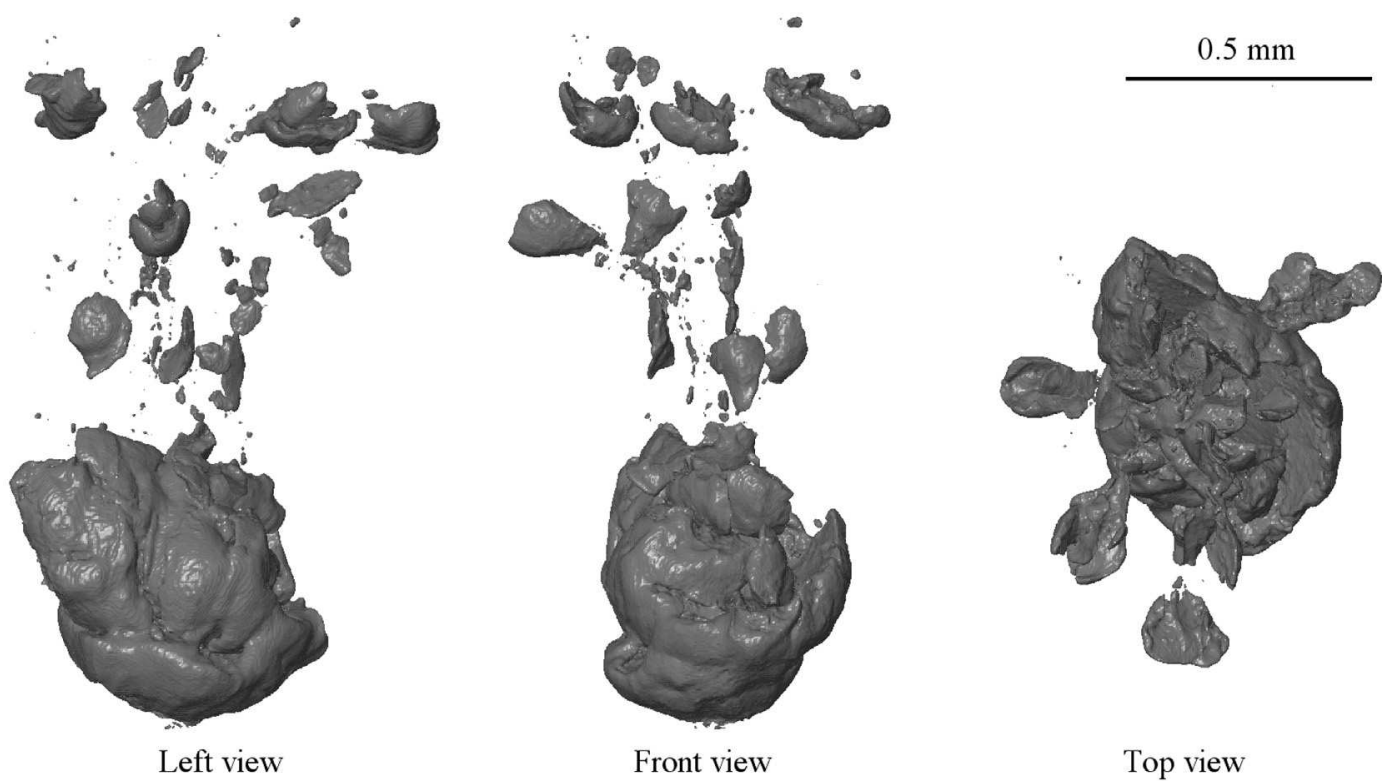

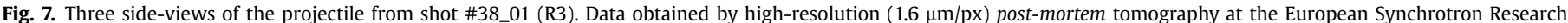

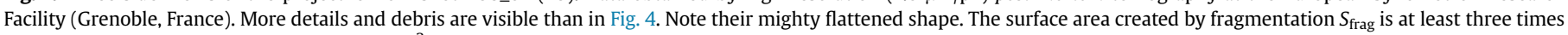
the original projectile one, i.e. $S_{\text {frag }} \geq 2.25 \mathrm{~mm}^{2}$.

shot \#39_09 (R3') comparatively to shot \#38_01 (R3) is $0.8 \mathrm{~J}$. In the case of shot \#21_01 (R3'), the extra amount is $1 \mathrm{~J}$. For both, this is roughly the energy required to entirely melt the projectile, i.e. $0.6 \mathrm{~J}$ [29].

Finally, the DOP diminution for shots at velocities beyond $3.2 \mathrm{~km} \mathrm{~s}^{-1}$ is mainly justified by the multiple fragmentation of the projectile resulting in the decreasing of the sectional density and the increasing of the shape coefficient in Eq. (5). Furthermore, past $4.1 \mathrm{~km} \mathrm{~s}^{-1}$, the melting of the debris is a serious hypothesis capable of explaining the DOP evolution.

\section{Conclusion}

We displayed new cratering and penetration experiments with $0.5-\mathrm{mm}$ diameter steel spherical projectiles and thick cylindrical graphite targets at velocities between 1.1 and $4.5 \mathrm{~km} \mathrm{~s}^{-1}$. Postmortem tomographies revealed that the projectiles were trapped into the target after the re-closing of the graphite. The characteristic dimensions of the craters such as volume, diameter and depth were measured and all of them increased with the impact velocity. But contrary to ductile materials, diameter and depth did not obey the $2 / 3$ power law and the volumes progressed as a function of the velocity to the power 4 instead of 2 .

Tomographies also provided the depth of penetration, the shape and the eventual debris of the steel projectile thanks to 3Dreconstruction. Their analysis highlighted four regimes of penetration behavior. First, the projectile is undeformed and the DOP increases with the striking velocity. Then, its plastic deformation modifies its shape which implies the strong DOP diminution until the fragmentation and the substantial melting of the projectile. To our knowledge, these different regimes have never been evidenced in graphite until now. Their discussion and simple calculations resulted in new insights into the penetration processes.

Finally, this paper attests the difficulty to study the behavior of graphite under high- and hyper-velocity impacts because it is highly dependent on the projectile mechanical properties. However, the use of laser facilities would enable to conduct projectilefree experiments. Previous works have indeed suggested the possibility to experimentally simulate impacts by laser-driven shocks. This point may pave the way for promising future works.

\section{Acknowledgments}

The authors express their gratitude to Stéphanie Tastet for performing the experiments and to Patrick Brelivet for the tomographies. They would also like to thank Claude Bianchi who accepted to revise the English of this paper.

\section{References}

[1] Cour-Palais B. A career in applied physics: Apollo through space station. Int J Impact Eng 1999;23(1, Part 1):137-68. http://dx.doi.org/http://dx.doi.org/10. 1016/S0734-743X(99)00069-X. Available from: http://www.sciencedirect. com/science/article/pii/S0734743X9900069X.

[2] Davison D, Cour-Palais B, Quan X, Holmquist T, Cohen LM, Ramsey R, et al. Computer models of micrometeoroid impact on fused silica glass mirrors. Int J Impact Eng 2003;29(110):203-14. Hypervelocity impact, http://dx.doi.org/ http://dx.doi.org/10.1016/j.ijimpeng.2003.09.017. Available from:, http:// www.sciencedirect.com/science/article/pii/S0734743X03001234.

[3] Michel Y, Chevalier JM, Durin C, Espinosa C, Malaise F, Barrau JJ. Hypervelocity impacts on thin brittle targets: experimental data and SPH simulations. Int J Impact Eng 2006;33:441-51.

[4] Tobin M, Andrew J, Haupt D, Mann K, Poco J, Satcher J, et al. Using silica aerogel to characterize hypervelocity shrapnel produced in high power laser experiments. Int J Impact Eng 2003;29(110):713-21. Hypervelocity impact; Available from: http://dx.doi.org/http://dx.doi.org/10.1016/j.ijimpeng.2003. 10.018. Available from: http://www.sciencedirect.com/science/article/pii/ S0734743X03001702.

[5] Lescoute E, Hallo L, Hébert D, Chimier B, Etchessahar B, Tikhonchuk VT, et al. Experimental observations and modeling of nanoparticle formation in laserproduced expanding ring. Phys Plasma 2008;15:1-11.

[6] Herrmann W, Jones AH. Correlation of hypervelocity impact data. In: Fifth symposium on hypervelocity impact; 1973. p. 389-438.

[7] Shanbing Y, Gengchen S, Qingming T. Experimental laws of cratering for hypervelocity impacts of spherical projectiles into thick target. Int J Impact Eng 1994;15(1):67-77. http://dx.doi.org/http://dx.doi.org/10.1016/S0734-743X(05) 80007-7. Available from: http://www.sciencedirect.com/science/article/pii/ S0734743X05800077.

[8] Piekutowski AJ, Forrestal MJ, Poormon KL, Warren TL. Penetration of 6061-t6511 aluminum targets by ogive-nose steel projectiles with striking velocities between 0.5 and 3.0 km/s. Int J Impact Eng 1999;23(1, Part 2):723-34. http://dx.doi.org/ http://dx.doi.org/10.1016/S0734-743X(99)00117-7. Available from: http:// www.sciencedirect.com/science/article/pii/S0734743X99001177. 
[9] Forrestal MJ, Piekutowski AJ. Penetration experiments with 6061-t6511 aluminum targets and spherical-nose steel projectiles at striking velocities between 0.5 and $3.0 \mathrm{~km} / \mathrm{s}$. Int J Impact Eng 2000;24(1):57-67. http://dx.doi. org/http://dx.doi.org/10.1016/S0734-743X(99)00033-0. Available from: http://www.sciencedirect.com/science/article/pii/S0734743X99000330.

[10] Pierazzo E, Artemieva N, Asphaug E, Baldwin EC, Cazamias J, Coker R, et al Validation of numerical codes for impact and explosion cratering: impacts on strengthless and metal targets. Meteorit Planet Sci 2008;43(12):1917-38. http://dx.doi.org/10.1111/j.1945-5100.2008.tb00653.x. Available from: http:// dx.doi.org/10.1111/j.1945-5100.2008.tb00653.x.

[11] Senft LE. Modeling impact cratering in layered surfaces. J Geophys Res 2007;112:1-18. http://dx.doi.org/10.1029/2007JE002894. Available from: http://dx.doi.org/10.1029/2007JE002894.

[12] Burt RR, Christiansen EL. Hypervelocity impact testing of transparent spacecraft materials. Int J Impact Eng 2003;29(110):153-66. http://dx.doi.org/ 10.1016/j.ijimpeng.2003.09.014. Hypervelocity impact; Available from: http:// www.sciencedirect.com/science/article/pii/S0734743X03001192.

[13] Anderson CE, Holmquist TJ. Application of a computational glass model to compute propagation of failure from ballistic impact of borosilicate glass targets. Int J Impact Eng 2013;56(0):2-11. Selected papers from the 2012 hypervelocity impact symposium, http://dx.doi.org/http://dx.doi.org/10.1016/ j.ijimpeng.2012.06.002. Available from:, http://www.sciencedirect.com/ science/article/pii/S0734743X12001236.

[14] Heine A, Weber KE, Wickert M. Experimental investigation of the penetration and perforation of building materials by projectiles. In: 26th International symposium on ballistics; 2011.

[15] Meyer CS. Modeling experiments of hypervelocity penetration of adobe by spheres and rods. Procedia Eng 2013;58(0):138-46. Proceedings of the 12th hypervelocity impact symposium, http://dx.doi.org/http://dx.doi.org/10.1016/ j.proeng.2013.05.017. Available from:, http://www.sciencedirect.com/science/ article/pii/S1877705813009235.

[16] Forrestal M, Frew D, Hanchak S, Brar N. Penetration of grout and concrete targets with ogive-nose steel projectiles. Int J Impact Eng 1996;18(5):465-76. http://dx.doi.org/http://dx.doi.org/10.1016/0734-743X(95)00048-F. Available from: http://www.sciencedirect.com/science/article/pii/0734743X9500048F.

[17] Numata D, Ohtani K, Anyoji M, Takayama K, Togami K, Sun M. \{HVI tests on \{CFRP\} laminates at low temperature. Int J Impact Eng 2008;35(12):1695-701. Hypervelocity impact proceedings of the 2007 symposium HVIS 2007, http://dx. doi.org/http://dx.doi.org/10.1016/j.ijimpeng.2008.07.055. Available from:, http://www.sciencedirect.com/science/article/pii/S0734743X08001991.

[18] Tennyson R, Lamontagne C. Hypervelocity impact damage to composites. Compos Part A: Appl Sci Manuf 2000;31(8):785-94. http://dx.doi.org/http://
dx.doi.org/10.1016/S1359-835X(00)00029-4. Available from: http://www. sciencedirect.com/science/article/pii/S1359835X00000294.

[19] Tanabe Y, Saitoh T, Akatsu T, Sawaoka A. Crater formation of carbon materials by impact of a high velocity sphere. Carbon 1995;33(11):1547-52. http:// dx.doi.org/10.1016/0008-6223(95)00113-R. Available from: http://www. sciencedirect.com/science/article/pii/000862239500113R.

[20] Latunde-Dada S, Cheesman C, Day D, Harrison W, Price S. Hypervelocity impacts into graphiteInglesfield $\mathrm{J}$, editor. Condensed matter and materials physics conference (CMMP10). Conference on condensed matter and materials physics (CMMP10). J Phys Conf Ser 2011;286:1-10. http://dx.doi.org 10.1088/1742-6596/286/1/012042. AWE; EPSRC; IOP Publishing; Dirac House, Temple Back, Bristol BS1 6BE, England: IOP Publishing Ltd., Univ Warwick, Coventry, England, Dec 14-16, 2010.

[21] Seisson G, Hébert D, Bertron I, Chevalier JM, Hallo L, Lescoute E, et al. Dynamic cratering of graphite: experimental results and simulations. Int J Impact Eng 2014;63(0):18-28. http://dx.doi.org/http://dx.doi.org/10.1016/j.ijimpeng 2013.08.001. Available from: http://www.sciencedirect.com/science/article/ pii/S0734743X13001565.

[22] Grady DE. The spall strength of condensed matter.J Mech Phys Solids 1988;36(3): 353-84. http://dx.doi.org/10.1016/0022-5096(88)90015-4. Available from: http://www.sciencedirect.com/science/article/pii/0022509688900154.

[23] www.poco.com; 2013.

[24] Seisson G, Hébert D, Bertron I, Chevalier JM, Lescoute E, Videau L et al. Dynamic behavior of a porous brittle material: experiments and modeling. Procedia Eng 2013;58(0):715-23. Proceedings of the 12th hypervelocity impact symposium, http://dx.doi.org/http://dx.doi.org/10.1016/j.proeng.2013.05.083.

[25] Bhadeshia H. Steels for bearings. Prog Mater Sci 2012;57(2):268-435. http:/ dx.doi.org/http://dx.doi.org/10.1016/j.pmatsci.2011.06.002. Available from: http://www.sciencedirect.com/science/article/pii/S0079642511000922.

26] Marsh S. LASL shock Hugoniot dataIn Los Alamos Scientific Laboratory series on dynamic material properties, vol. 5. University of California Press; 1980 ISBN 9780520040083. Available from: http://books.google.fr/books?id=PCJtmM91JcC.

[27] Schneider E, Stilp A. Projectile penetration into low density media. In: 8th International symposium on ballistics; 1984.

[28] Trucano TG, Grady DE. Impact shock and penetration fragmentation in porous media. Int J Impact Eng 1995;17(46):861-72. Hypervelocity impact proceedings of the 1994 symposium, http://dx.doi.org/http://dx.doi.org/10.1016 0734-743X(95)99906-8. Available from:, http://www.sciencedirect.com/ science/article/pii/0734743X95999068.

[29] Chase MW. NIST-JANAF thermochemical tables. 4th ed., vol. 2. American Chemical Society; 1998. 